\title{
The Impact of Environmental Governance on the Development of Fishery Economy-The Intermediary Role of Technological Innovation
}

\author{
Na Hou ${ }^{1}$, Qianying Zhu ${ }^{1}$, Jinlin Yang ${ }^{1}$, Dahong Zhang ${ }^{1}$, Wenwen Liu ${ }^{1, *}$ and Hong Chang ${ }^{2, *}$ \\ 1 School of Economics and Management, Beijing Forestry University, Beijing 100083, China; \\ houna@bjfu.edu.cn (N.H.); zhuqianyingz@163.com (Q.Z.); yangjinlin96@163.com (J.Y.); \\ zhangdahong591120@163.com (D.Z.) \\ 2 School of Economics, Capital University of Economics and Business, Beijing 100070, China \\ * Correspondence: wenwensummer@163.com (W.L.); changh@cueb.edu.cn (H.C.)
}

check for

updates

Citation: Hou, N.; Zhu, Q.; Yang, J.; Zhang, D.; Liu, W.; Chang, H. The Impact of Environmental Governance on the Development of Fishery

Economy-The Intermediary Role of Technological Innovation.

Sustainability 2021, 13, 11378. https:// doi.org/10.3390/su132011378

Academic Editor: Francesco Tiralongo

Received: 1 September 2021

Accepted: 12 October 2021

Published: 15 October 2021

Publisher's Note: MDPI stays neutral with regard to jurisdictional claims in published maps and institutional affiliations.

Copyright: (c) 2021 by the authors. Licensee MDPI, Basel, Switzerland. This article is an open access article distributed under the terms and conditions of the Creative Commons Attribution (CC BY) license (https:/ / creativecommons.org/licenses/by/ $4.0 /)$.

\begin{abstract}
In the context of the "new normal" of China's economic development, it is urgent to solve the contradiction between fishery development and environmental protection. To promote the construction of a modern fishery power, we must return to ecological priority. Based on this, the research used relevant data samples from various provinces during 2004-2017. The level of fishery economic development is measured using fishery added value and total fishery output value; the industrial pollution control investment and environmental pollution control investment represent the intensity of environmental control; the relationship between environmental governance and fishery economic development is explored, and the intermediary role of technological innovation is further analyzed. Empirical results show that environmental governance has a significant positive impact on fishery economic development, and this influence shows both spatial and temporal heterogeneity, regionally showing the distribution characteristic of "in the eastern region > in the central region > in the western region", and the time series show the "strengthened influence - weakened influence" i.e., "inverted U" variations. In addition, technological innovation plays a certain intermediary role in the impact of environmental governance on fishery economic development. The research provides a theoretical basis for breaking through the bottleneck of fishery development and realizing high-quality and sustainable development.
\end{abstract}

Keywords: environmental governance; fishery economic development; technological innovation; regional heterogeneity

\section{Introduction}

In March 2020, the PRC General Office of the State Council issued Guiding Opinions on the Construction of Modern Environmental Governance System, which pointed out that the concept of green development should be firmly established; the benign interactions between government governance, social adjustment and enterprise autonomy should be accomplished; the mechanism and system should be improved and the source treatment needs to be strengthened, thus forming a joint force in order to provide a strong institutional guarantee for the radical improvement of the ecological environment, leading to the construction of ecological civilization and a beautiful China. It shows that environmental governance is of great importance for building a beautiful China and forming a modern national governance system [1].

In a narrow sense, environmental governance refers to the governance of the natural ecological environment; in a broad sense, it refers to the environmental governance model, which is a governance activity integrating economic governance, political governance, cultural governance and social governance [2]. Environmental governance is determined by the objective needs of economic and social development, and is the fundamental requirement of ecological civilization construction [3]. There is a trade-off between 
environmental governance and economic development [4]. Environmental governance can promote economic growth in two ways: on the one hand, environmental governance can promote economic growth through a variety of economic activities; on the other hand, environmental governance can improve the environmental carrying capacity and promote economic development [5].

Fishery economy is an important part of marine economy, and it is also the industry with the fastest development and the best benefit in agriculture. Fishery modernization is an important part of agricultural modernization, and a key link in building a harmonious society and promoting rural revitalization [6]. China is a big fishery country. In 2017, the total output of China's aquatic products accounted for more than one-third of the world's total aquatic products, and the fishery output value reached CNY 1200.291 billion. In addition, China is also the largest aquaculture country in the world, accounting for more than $70 \%$ of the world's total output. Fishery has made an important contribution to ensuring national food security and increasing the income of farmers and fishermen. At present, fishery has become an important pillar industry to promote the development of China's national economy [7].

In recent years, the external pollution has seriously affected the environmental quality of the fishery waters, ecological disasters and other problems have caused a huge threat to the fishery economy, and the fishery economic losses caused by environmental pollution are serious [7]. In addition, according to the existing literature, the increase of per capita disposable income, population and urbanization level will increase the demand for aquatic products. With the continuous improvement of people's living standards in China, the output and consumption of aquatic products in China are also rising significantly [8]. From the actual development of China's fisheries, the growth rate of fishery production is far lower than the added value of consumption. The contradiction between fishery production and consumption has seriously hindered the development of China's fishery economy.

Fishery is an important part of the marine economy and plays an important role in ensuring the supply of aquatic products, alleviating the pressure on food security, and improving the dietary structure of residents. The global long-term extensive marine fishery development model has caused varying degrees of damage to the ecological environment, and the deterioration of the ecological environment will in turn restrict the healthy and sustainable development of fisheries. The sustainable development of fishery economy is a brand-new theoretical system, which refers to the overall planning and balance between fishery economy, environmental protection and social development in order to achieve a new fishery development model for the harmonious development of man and nature. At present, countries around the world are paying more and more attention to environmental governance issues, and are making continuous efforts to achieve sustainable development; at the same time, environmental issues have seriously hindered the development of fishery economy, causing the people's growing needs for a better life to be unsatisfied. Fully understanding and using the interaction mechanism between the environment and fishery economy development is of great significance to the realization of sustainable development. Through the analysis of the relationship between the two, this paper explains the impact mechanism of environmental governance on fishery economic growth, explains the possible intermediary role of technological innovation, fills the gap in this research field, and has certain innovative and practical value.

\section{Literature Review}

Forster and other scholars have been relatively early in the research on how environmental governance affects economic growth. By constructing the Harrod model, D'Arge [9] analyzed the interaction mechanism between economic growth and natural environment, and thought that domestic and foreign economic policy and environmental policy are complementary and inseparable. Later, Forster $[10,11]$ further studied the relationship between environmental governance and economic growth based on the neoclassical growth model in his two articles in 1972 and 1973. Forster believed that if certain environmental gover- 
nance is carried out, it may help to maximize the welfare of consumers, but environmental governance will also lead to the reduction of balanced consumption and capital stock.

In China, the research on this aspect started relatively late. $\mathrm{Xu}$ and $\mathrm{Mu}$ [12] first proposed that environment is a special asset for the public service of all mankind and the destruction of environment means the loss of this asset, and then the disappearance of GDP and people's welfare. In addition, through the international comparison of environmental governance mode, they thought that environmental governance cannot be treated as a purely technical problem. On this basis, they put forward the way of environmental governance suitable for China's national conditions. Zhang and Zuo [13] introduced energy and environment into the production function, and established an endogenous economic growth model under the dual constraints of energy and environment. Through theoretical analysis, they showed that the improvement of environmental quality as a factor input can promote economic growth, and believed that only by maintaining the natural environment and ecological balance can China achieve sustainable economic growth. By building a two-stage model of the relationship between environmental governance investment and economic growth, combined with empirical analysis, Dai et al. [14] found that China has basically entered the second development stage of environmental governance investment to promote economic growth-the late promotion stage. They pointed out that the promotion effect of environmental governance investment on economic growth can be shown in two aspects: on the one hand, it can promote economic growth by reducing the scale effect, improving the structure effect and promoting the technology effect and other economic activities; on the other hand, it can promote economic growth by improving the environmental carrying capacity. By establishing an endogenous growth model of human capital, Huang and Chen [15] analyzed the environment and environmental pollution control under the framework of endogenous growth, and found that the increasing share of investment in environmental pollution control has a negative impact on economic growth to a certain extent, but it is a necessary price to achieve sustainable development, and China still needs to strengthen environmental pollution control in the future, to improve the efficiency of environmental governance and to strive to fundamentally reverse the severe situation of environmental deterioration. By establishing a long-term equilibrium model of industrial pollution environmental governance investment and economic growth, Chen et al. [16] explained the mechanism of industrial pollution governance in promoting economic growth in the long run. The results showed that in the long run, when the governance investment increases less, environmental governance has a restraining effect on economic growth, and when the governance investment increases more, it has a promoting effect on economy; however, with the increase of governance investment, the economic growth effect is on the decline. Zhang [17] used the Solow model with environmental governance factors and introduced environmental governance funds and labor factors to analyze the balanced impact of environmental governance on economic growth. The results showed that in the long run, the environmental governance investment has a significant positive effect on economic growth, but in the short run, the increase in the share of investment in environmental governance has a negative effect on economic growth. Therefore, while adhering to the long-term investment in environmental pollution control, it is necessary to coordinate the relationship between environmental governance and economic development in the short run. Based on the "production-R\&D" two-sector model, Chang and Wang [18] arranged the mathematical logic among environmental regulation, technological innovation and economic growth, and explained that the impact of environmental regulation on economic growth is related to technological innovation, and the impact of environmental regulation on economic growth has the threshold of technological innovation: when the level of technological innovation is low, environmental regulation will inhibit economic growth; when the level of technological development is high, environmental regulation will promote economic growth.

Environmental economist Yao Jian [19] believes that the environment-economy system has two sub-systems, environment system and economy system, which is a complex system 
having natural structure and function through material circulation, energy flow, exchange or conversion of information and value, interdependence, interweaving and coupling. It is restricted by the laws of nature and possesses natural attributes, and at the same time, it is governed by objective economic laws and possesses social attributes. The environment-economy system has four basic elements: population, capital (or funds), resources and technology. From the structural point of view, the four basic elements of the environment-economy system form three subsystems: environment subsystem, economy subsystem and technology subsystem. The interaction of the three makes the environmenteconomy system possess the four major functions of material circulation, energy flow, information transmission and value appreciation. Grossman and Krueger [20] conducted an empirical study on the relationship between environmental quality and per capita income of residents and found that "pollution increases with the increase of per capita income at low income levels, and decreases with the increase of per capita income at high income levels". Based on Kuznets's research, Panayotou [21] proposed the Environmental Kuznets Curve (EKC) to describe the relationship between environmental quality and per capita income. However, while many countries and regions have achieved rapid economic growth, they have also led to the excessive development and consumption of ecological environment resources, which further caused serious environmental pollution and ecological damage. Since then, scholars have begun to study the coordinated development between economic development and ecological environment quality. Sadik-Zada and Gatto [22] combines two strands of literature- the Resource Curve and the Environmental Kuznets Curve hypotheses-to put forward a novel three-sector model, which provides a common ground for structuralist, institutional and purely economic analyses of carbon footprint. To address the challenge of merging two concepts-the inward-oriented EKC hypothesis and the pollution haven hypothesis-Sadik-Zada and Ferrari [23] set out a simple variational model, which identifies the structural composition of the economy and the level of economic development as the primary determinants of the magnitude of the domestic environmental degradation. The central implication of this theoretical model is the recognition of the fact that countries at different stages of economic development have different thresholds of environmental degradation.

In recent years, the research on how environmental governance affects economic growth has gradually turned to the impact of environmental governance on a specific industry, but the research related to the development of fishery economy is fewer in number. Ding et al. [24] studied the relationship between the efficiency of marine economic production and the efficiency of environmental governance, and proposed that in the development of marine economy, coastal provinces and cities should fully consider the impact of policy, environment and economic development of adjacent areas on their own areas, make rational use of their positive role and avoid their adverse effects. However, there is still a lack of relevant research on the impact of environmental governance on fishery economic growth from the perspective of empirical analysis. In this paper, the research of environmental governance on fishery economic growth fills the gap in this field and has a certain degree of innovation. At present, some scholars have carried out relevant analysis on how fishery economy is affected by the environment. These studies confirm the impact of environmental governance on fishery economic growth from the side. Huang et al. [25] were the first to elaborate on the serious harm of environmental pollution to fishery output, and considered that its impact is mainly manifested in the following aspects: environmental pollution leads to the death of aquatic products, red tide leads to serious fishery losses, pollution leads to the increase of the number and varieties of residual harmful substances in aquatic products, and it damages human health. They also believed that to increase the output of aquatic products, we should first strengthen the protection of fishery environment. Jia [26] further pointed out that the pollution that caused fishery losses included river and lake pollution, pond ecological risk, fishery self-pollution and so on. At the same time, he thought that the fine to the polluting unit could only play a temporary but not permanent role, and we should be determined to eliminate the pollution in the "factory wall". Based 
on the analysis of the development of fishery resources and the impact of marine pollution on fishery economy in Weifang, Shandong Province, Han [27] put forward suggestions on marine environmental governance, including establishing and improving the total emission control system of main rivers into the sea, strengthening the environmental detection ability of coastal waters and main rivers into the sea, and increasing investment in marine environmental pollution governance. Bi and Duan [28] divided the factors that affect the fishery ecological environment into non-biological factors, biological factors and human factors, further clarified the sources of fishery ecological environment pollution include land pollution sources, marine pollution sources and aquaculture pollution, which indicated that not only marine environmental pollution but also any other environmental pollution will affect the development of fishery economy, confirmed from the side that the environmental governance of all industries will affect the economic growth of fisheries, finally put forward the anti-pollution strategy of paying equal attention to both land and sea, and prevention and control. Fu et al. [29] studied the cooperative governance model of marine fishery environmental pollution and proposed that marine fishery waters belong to public goods, with integrity and complexity. Therefore, to consider the pollution of marine fishery environment, we should proceed from the overall situation and achieve the diversification, institutionalization and mutual trust in the governance process and maximization of public interests. The protection of fishery environment requires the government to fully mobilize the market and social forces through various means such as industrial pollution control investment and environmental pollution control investment. Cui et al. [7] described in detail the environmental problems faced by the current fishery economic development: external pollution seriously affects the environmental quality of fishery waters, and clearly put forward that the planning goal of fishery development is to harness the ecological environment, curb the momentum of environmental deterioration, and rationally develop and utilize fishery waters.

To sum up, existing studies can analyze the relationship between environmental governance and fishery economic development from two paths. Some studies suggest that environmental governance will affect economic growth, and fishery is an important industry in the national economic system because inland fish and fishery make substantial contributions to individuals, society and the environment by providing food and livelihoods for billions of people worldwide [30,31], so that environmental governance will also affect the development of fishery economy. Other studies have found that the development of fishery economy will be restricted by environmental pollution, and environmental damage will hinder the development of fishery economy, or in other words, environmental governance will promote the growth of fishery economy. However, it should be noted that these two research paths cannot directly explain the impact of environmental governance on the development of fishery economy, which are explored mainly through speculation, common sense and other non-academic methods, and there is no direct empirical research on the relationship between environmental governance and fishery economic development. Based on some methods and conclusions of existing studies, this paper makes a direct analysis on the impact of environmental governance on fishery economic growth through empirical test, and explains the impact mechanism of environmental governance on fishery economic growth, so as to confirm the relevant views.

\section{Model Building and Data Description}

\subsection{Model Building and Indicator Selection}

\subsubsection{Econometric Model and Variable Definition}

In order to further investigate the impact of environmental governance on fishery economic growth and its mechanism from the practical level, this paper constructs the following benchmark empirical model:




In the equation, the explained variable is the level of fishery economic growth, which is respectively expressed by fishery added value (afis) and total fishery output value ( $t$ fis). The larger the fishery added value or total fishery output value, the higher the level of fishery economic development. The explanatory variable of the model is environmental governance. Here, we also use two proxy variables, namely, the amount of investment in industrial pollution control (ind $u$ ) and the amount of investment in environmental pollution control (poll). Generally speaking, the greater the total amount of investment in pollution control, the greater the intensity of environmental governance. Considering the reliability of the research conclusion, the proportion of investment in environmental pollution control in GDP, the intensity of wastewater discharge and the intensity of sulfur dioxide emission are used as the agent variables for environmental treatment in robustness test of the model.

The control variables include the following: (1) Consumption (consume), which is a measure of the impact of residents' consumption on the level of fishery economic growth. The increase of consumption level can improve the overall level of economic development, and then promote fishery economic growth to a certain extent. This paper mainly studies the development of fishery economy, so we chose the proportion of retail sales of consumer goods at and below the county level in the whole country to measure the consumption level of residents. (2) Income level (income), which is used to control the impact of residents' income on fishery economic growth. Considering that fishery is mainly distributed in rural areas, it is expressed by the per-capita income level of rural residents. Generally speaking, the improvement of per-capita income level of rural residents can effectively promote the development of rural fishery economy. (3) Greening construction level (forest): considering the influence of greening degree on fishery economic growth, we chose afforestation area to measure regional greening construction level. (4) Investment intensity (invest): local investment intensity is an important guarantee of regional economic growth, and its change will have an important impact on the economic growth of a country or region. This paper selects the total investment in rural fixed assets to measure the regional investment intensity. (5) Rural electricity consumption (elec), which is used to measure the impact of the overall rural electricity consumption on the fishery economy. How much electricity is used in rural areas reflects the development of the rural economy to a certain extent. (6) Aquaculture area of aquatic products (cult) and (7) per-capita output of aquatic products (prod), which can well reflect the development of fishery economy in a region. The subscript $i$ indicates the region, $t$ indicates the time, $\alpha_{0}$ is a constant term, $\alpha_{1}$ and $\alpha_{2}$ indicate the coefficients of explanatory variable and control variable, $\varepsilon_{i t}$ is stochastic error.

Besides exploring the important role of environmental governance on fishery economic growth, this paper also attempts to investigate the impact mechanism of environmental governance on fishery economy, and further test the rationality of theoretical analysis. According to the theoretical analysis, technological innovation can play a certain mediating role between environmental governance and fishery economic growth. In order to test the practical significance of theoretical analysis, according to the basic principle of mediating effect model, based on benchmark regression model, the following empirical model is constructed:

$$
\begin{gathered}
\operatorname{afis}_{i t}\left(t f i s_{i t}\right)=\beta_{0}+\beta_{1} i n d u_{i t}\left(\text { poll }_{i t}\right)+\beta_{2} \text { pat }_{i t}+\beta_{3} \operatorname{control}_{i t}+\varepsilon_{i t} \\
\text { pat }_{i t}=\theta_{0}+\theta_{1} \text { afi }_{i t}\left(\text { tfis }_{i t}\right)+\theta_{2} \text { control }_{i t}+\varepsilon_{i t}
\end{gathered}
$$

where technological innovation (pat) is indicated by the number of patents granted, $\beta_{j}$ and $\theta_{j}$ indicate the coefficients of each variable, and the explanation of other related variables is the same as Formula (1). Refer to the mediating effect test method proposed by Wen et al. [32] in 2014, according to the specific empirical model set in this paper, the process of mediating effect test is briefly explained: The first step is to estimate Formula (1) and test the total effect of environmental governance on fishery economy; if $\alpha_{1}$ is significant, then the influence of the total effect is tenable, and the next test is carried out. The second step is to estimate Formulas (2) and (3); if both $\beta_{2}$ and $\theta_{1}$ are significant, then the indirect 
effect is significant, go to the third step; if at least one of them is not significant, the Bootstrap method is used to test $H_{0}: \beta_{2}=0$ directly-if it is significant, then the indirect effect is significant, go to the third step; otherwise, the indirect effect is not significant. The third step is to test the coefficient $\beta_{1}$ of Formula (2); if it is significant, the direct effect of environmental governance is significant; if it is not significant, the direct effect is not significant, indicating that there is only mediating effect. The fourth step is to compare the sign of $\beta_{2} \theta_{1}$ and $\beta_{1}$, if the sign is same, there is a partial mediating effect; if the sign is different, there is a suppressing effect.

\subsubsection{Data Source}

Considering the main research objectives of this paper, combined with the data availability, this paper selects the panel data of China's provinces, autonomous regions and municipalities from 2004 to 2017 to make an empirical test on the above analysis. The main data sources of this paper are China Statistical Yearbook, China Rural Statistical Yearbook, China Agriculture Yearbook, etc.

\subsection{Descriptive Statistics of Variables}

Table 1 is the descriptive statistical results of the main variables in this paper. The statistical results show that, in 420 samples, the vast majority of samples have all variable data, so the reliability of variables and data can be guaranteed. In addition, due to the uneven distribution of fishery economic development, the values of various variables related to fishery development in areas with rich water resources differ greatly from those in areas with poor water resources, resulting in a smaller minimum value of variables and larger standard deviation of variables, and the mean value of variables is closer to the lower limit of values.

Table 1. Descriptive statistics of variables.

\begin{tabular}{cccccc}
\hline Variables & $\begin{array}{c}\text { Sample } \\
\text { Capacity }\end{array}$ & $\begin{array}{c}\text { Maximum } \\
\text { Value }\end{array}$ & $\begin{array}{c}\text { Minimum } \\
\text { Value }\end{array}$ & Mean Value & $\begin{array}{c}\text { Standard } \\
\text { Deviation }\end{array}$ \\
\hline afis & 416 & 1359.6 & 0 & 162.92 & 221.28 \\
tfis & 420 & 1623.4 & 0 & 246.62 & 345.40 \\
indu & 420 & 1416.46 & 1.92 & 196.82 & 188.60 \\
poll & 420 & 506 & 0.18 & 20.52 & 30.66 \\
ipoll & 420 & 263.14 & 0.48 & 13.48 & 14.41 \\
wast & 420 & 679.84 & 47.54 & 163.79 & 93.66 \\
sulf & 420 & 783.76 & 0.60 & 84.34 & 100.37 \\
pat & 420 & 332.65 & 0.07 & 27.68 & 49.17 \\
consume & 420 & 52.6 & 5.9 & 33.14 & 10.75 \\
income & 420 & 112.95 & 1.72 & 7.97 & 6.97 \\
forest & 419 & 812.22 & 0 & 100.07 & 119.83 \\
invest & 420 & 5767.8 & 2.1 & 531 & 719.14 \\
elec & 420 & 1888 & 2.9 & 232.43 & 351.85 \\
cult & 420 & 1271.1 & 0.2 & 61.29 & 134.27 \\
prod & 420 & 1152.2 & 2.9 & 254.32 & 256.50 \\
\hline
\end{tabular}

\section{Empirical Analysis}

\subsection{Regression Results}

Based on the relevant data samples of each province from 2004 to 2017, the level of fishery economic development is measured by fishery added value and total fishery output value, the investment in industrial pollution control and the investment in environmental pollution control represent the intensity of environmental governance, the control variables related to fishery economic development are added to each column. Through Hausman test, the fixed effect (FE) model is used to estimate Formula (1) to test the quantitative relationship between environmental governance and fishery economic growth. In order to 
facilitate comparison, this paper also gives the estimation results by using ordinary least squares (OLS) method. The empirical results are shown in Table 2.

Table 2. The influence of environmental governance on fishery economy.

\begin{tabular}{|c|c|c|c|c|c|c|c|c|}
\hline Variables & Model 1 & Model 2 & Model 3 & Model 4 & Model 5 & Model 6 & Model 7 & Model 8 \\
\hline & \multicolumn{2}{|c|}{ OLS regression } & \multicolumn{2}{|c|}{ FE regression } & \multicolumn{2}{|c|}{ OLS regression } & \multicolumn{2}{|c|}{ FE regression } \\
\hline & \multicolumn{4}{|c|}{ Explained variable: afis } & \multicolumn{4}{|c|}{ Explained variable: tfis } \\
\hline indu & $\begin{array}{c}0.280 * * * \\
(6.30)\end{array}$ & & $\begin{array}{c}0.274^{* * *} \\
(5.01)\end{array}$ & & $\begin{array}{c}0.212 * * * \\
(4.14)\end{array}$ & & $\begin{array}{c}0.190 * * * \\
(3.60)\end{array}$ & \\
\hline poll & & $\begin{array}{c}1.174^{* * * *} \\
(5.33)\end{array}$ & & $\begin{array}{c}1.105^{* * *} \\
(5.18)\end{array}$ & & $\begin{array}{c}0.850^{* * *} \\
(4.00)\end{array}$ & & $\begin{array}{c}0.847^{* * *} \\
(4.13)\end{array}$ \\
\hline consume & $\begin{array}{c}1.934^{* *} \\
(2.46)\end{array}$ & $\begin{array}{c}2.455^{* * *} \\
(3.03)\end{array}$ & $\begin{array}{l}0.585 \\
(0.33)\end{array}$ & $\begin{array}{l}1.133 \\
(0.64)\end{array}$ & $\begin{array}{l}2.122 * \\
(1.69)\end{array}$ & $\begin{array}{c}2.597^{* *} \\
(2.05)\end{array}$ & $\begin{array}{l}2.113 \\
(1.25)\end{array}$ & $\begin{array}{l}2.512 \\
(1.49)\end{array}$ \\
\hline income & $\begin{array}{l}1.834 \text { * } \\
(1.87)\end{array}$ & $\begin{array}{c}1.817^{*} \\
(1.83)\end{array}$ & $\begin{array}{l}1.664 \text { * } \\
(1.67)\end{array}$ & $\begin{array}{l}1.720 * \\
(1.73)\end{array}$ & $\begin{array}{c}2.750 * * * \\
(2.83)\end{array}$ & $\begin{array}{c}2.699 * * * \\
(2.78)\end{array}$ & $\begin{array}{c}2.662 * * * \\
(2.77)\end{array}$ & $\begin{array}{c}2.656^{* * *} \\
(2.78)\end{array}$ \\
\hline forest & $\begin{array}{l}-0.123 \text { * } \\
(-1.89)\end{array}$ & $\begin{array}{l}-0.098 \\
(-1.46)\end{array}$ & $\begin{array}{l}0.056 \\
(0.63)\end{array}$ & $\begin{array}{l}0.016 \\
(0.18)\end{array}$ & $\begin{array}{l}-0.028 \\
(-0.35)\end{array}$ & $\begin{array}{l}-0.040 \\
(-0.49)\end{array}$ & $\begin{array}{l}0.072 \\
(0.83)\end{array}$ & $\begin{array}{l}0.045 \\
(0.53)\end{array}$ \\
\hline invest & $\begin{array}{c}-0.034^{* * *} \\
(-3.26)\end{array}$ & $\begin{array}{c}-0.036^{* * *} \\
(-3.49)\end{array}$ & $\begin{array}{c}-0.023 \\
(-1.90)\end{array}$ & $\begin{array}{c}-0.036^{* * *} \\
(-2.98)\end{array}$ & $\begin{array}{c}-0.065^{* * *} \\
(-5.99)\end{array}$ & $\begin{array}{c}-0.071^{* * *} \\
(-6.62)\end{array}$ & $\begin{array}{c}-0.063^{* * *} \\
(-5.36)\end{array}$ & $\begin{array}{c}-0.072^{* * *} \\
(-6.26)\end{array}$ \\
\hline elec & $\begin{array}{c}0.175^{* * *} \\
(6.05)\end{array}$ & $\begin{array}{c}0.209 * * * \\
(7.27)\end{array}$ & $\begin{array}{c}0.335 * * * \\
(5.84)\end{array}$ & $\begin{array}{c}0.346^{* * * *} \\
(6.08)\end{array}$ & $\begin{array}{c}0.511 * * * \\
(12.05)\end{array}$ & $\begin{array}{c}0.539 * * * \\
(12.87)\end{array}$ & $\begin{array}{c}0.591^{* * *} \\
(10.70)\end{array}$ & $\begin{array}{c}0.596^{* * *} \\
(10.91)\end{array}$ \\
\hline cult & $\begin{array}{c}0.392 * * * \\
(10.28)\end{array}$ & $\begin{array}{c}0.412 \text { *** } \\
(10.45)\end{array}$ & $\begin{array}{c}0.481^{* * *} \\
(4.55)\end{array}$ & $\begin{array}{c}0.413^{* * *} \\
(3.88)\end{array}$ & $\begin{array}{c}0.593^{* * * *} \\
(9.34)\end{array}$ & $\begin{array}{c}0.591^{* * *} \\
(9.09)\end{array}$ & $\begin{array}{c}0.564^{* * * *} \\
(5.54)\end{array}$ & $\begin{array}{c}0.512 \text { *** } \\
(5.01)\end{array}$ \\
\hline prod & $\begin{array}{c}0.171^{* * *} \\
(3.40)\end{array}$ & $\begin{array}{c}0.196^{* * *} \\
(3.86)\end{array}$ & $\begin{array}{l}0.051 \\
(1.00)\end{array}$ & $\begin{array}{l}0.080 \\
(1.58)\end{array}$ & $\begin{array}{c}0.183^{* * *} \\
(3.64)\end{array}$ & $\begin{array}{c}0.200^{* * * *} \\
(4.00)\end{array}$ & $\begin{array}{c}0.134^{* * *} \\
(2.72)\end{array}$ & $\begin{array}{c}0.154^{* * *} \\
(3.17)\end{array}$ \\
\hline Sample capacity & 415 & 415 & 415 & 415 & 419 & 419 & 419 & 419 \\
\hline Hausman & 50.59 & 51.24 & 50.59 & 51.24 & 42.49 & 39.71 & 42.49 & 39.71 \\
\hline $\mathrm{P}$ & 0 & 0 & 0 & 0 & 0 & 0 & 0 & 0 \\
\hline
\end{tabular}

Note: ${ }^{*}{ }^{* *}$ and ${ }^{* * *}$ respectively indicate that the estimated coefficients are significant at the levels of $0.1,0.05$ and 0.01 , and the constant term estimation is omitted.

When fishery added value is used as the explained variable, whether using OLS method or FE model, both the investment in industrial pollution control and the investment in environmental pollution control have significant positive effects on fishery added value; similarly, when total fishery output value is used as the explained variable, whether using OLS method or FE model, both the investment in industrial pollution control and the investment in environmental pollution control have significant positive effects on total fishery output value. To sum up, whether the level of fishery economic development is measured only by the amount of investment in industrial pollution control or by the amount of investment in environmental pollution control, the increase of explanatory variables will significantly increase the level of fishery economic development, that is, environmental governance can significantly promote fishery economic development.

\subsection{Mediating Effect Test}

In order to further explore the specific impact mechanism of environmental governance on fishery economic development, this paper uses fixed effect (FE) model to estimate Formulas (2) and (3). According to the estimated results in Table 3, when two variables of investment in industrial pollution control and technological innovation are used to explain the level of fishery economic development, whether fishery added value or total fishery output value is used to measure the level of fishery economic development, both of two variables have significant positive effects; when two variables of investment in environmental pollution control and technological innovation are used to explain the level of fishery economic development, whether fishery added value or total fishery output value is used to measure the level of fishery economic development, both of two variables have significant positive effects; when investment in industrial pollution control or investment 
in environmental pollution control is used to explain technological innovation, the increase of the investment will significantly improve the level of technological innovation.

Referring to the mediating effect test method, in the first step (Table 2), the positive effect of environmental governance on fishery economic development is very significant (namely, $\alpha_{1}$ is significant), and the influence of the total effect is tenable. In the second step (Table 3), the positive effect of technological innovation on fishery economic development is very significant when considering the environmental governance factor (namely, $\beta_{2}$ is significant), while the positive effect of environmental governance on technological innovation is also very significant (namely, $\theta_{1}$ is significant); thus, the indirect effect is significant. In the third step (Table 3 ), the positive effect of environmental governance on fishery economic development is very significant when considering the technological innovation factor (namely, $\beta_{1}$ is significant); thus, the direct effect of environmental governance is significant. In the fourth step (Table 3 ), the sign of $\beta_{2} \theta_{1}$ and $\beta_{1}$ is obviously the same; thus, there is a partial mediating effect. According to the test results of mediating effect, this paper proves that technological innovation can play a certain mediating role between environmental governance and fishery economic development.

Table 3. Mediating effect test.

\begin{tabular}{|c|c|c|c|c|c|c|}
\hline Variables & Model 1 & Model 2 & Model 3 & Model 4 & Model 5 & Model 6 \\
\hline & afis & tfis & afis & tfis & pat & pat \\
\hline indu & $\begin{array}{c}0.226^{* * *} \\
(4.09)\end{array}$ & $\begin{array}{c}0.109 * * \\
(2.12)\end{array}$ & & & $\begin{array}{c}0.057^{* * *} \\
(4.63)\end{array}$ & \\
\hline poll & & & $\begin{array}{c}0.963 \text { *** } \\
(4.55)\end{array}$ & $\begin{array}{c}0.623^{* * *} \\
(3.18)\end{array}$ & & $\begin{array}{c}0.156^{* * *} \\
(3.23)\end{array}$ \\
\hline pat & $\begin{array}{c}0.858^{* * *} \\
(3.81)\end{array}$ & $\begin{array}{c}1.435^{* * *} \\
(6.87)\end{array}$ & $\begin{array}{c}0.907^{* * *} \\
(4.10)\end{array}$ & $\begin{array}{c}1.432^{* * *} \\
(7.00)\end{array}$ & & \\
\hline Control variables & controlled & controlled & controlled & controlled & controlled & controlled \\
\hline Sample capacity & 415 & 419 & 415 & 419 & 419 & 419 \\
\hline
\end{tabular}

\subsection{Endogeneity Analysis}

The model analysis above may have some endogenous problems. First is that of missing variables. In the analysis of the relationship between environmental governance and fishery economic growth, although some variables related to fishery economy are controlled, considering that Formula (1) does not take all the factors affecting fishery economic growth into account, some important variables affecting fishery economic growth may be omitted. Second is mutual causation. Environmental governance will affect the fishery economic development, and the improvement of fishery economic development level will also affect environmental governance. Therefore, there may be a mutual causation relationship between environmental governance and fishery economic growth, which leads to the error of estimation results. For this reason, we further use the Hausman test to judge the endogenous problems of the model. If test results reject the hypothesis that all variables are exogenous, we can judge that the model have endogenous problems. In order to overcome this endogenous problem in the model and make the estimation results better reflect the actual impact level of environmental governance on fishery economic growth, the iterative GMM method is used to estimate the model, and the Hansen test is used to judge that the instrumental variables selected in this paper are also appropriate. The specific test results are shown in Table 4 . In addition, from the estimation results of the model, the significance level and direction of the estimated coefficients of each variable have not changed significantly, so it can be basically judged that the estimation results of this paper are robust. 
Table 4. Endogenous test.

\begin{tabular}{|c|c|c|c|c|c|c|c|c|c|c|}
\hline Variables & Model 1 & Model 2 & Model 3 & Model 4 & Model 5 & Model 6 & Model 7 & Model 8 & Model 9 & Model 10 \\
\hline & afis & tfis & afis & tfis & afis & tfis & afis & tfis & afis & tfis \\
\hline indu & $\begin{array}{c}0.265^{* * *} \\
(3.72)\end{array}$ & $\begin{array}{c}0.528^{* * *} \\
(4.95)\end{array}$ & & & & & & & & \\
\hline poll & & & $\begin{array}{c}3.329 * * * \\
(4.25)\end{array}$ & $\begin{array}{c}4.188 * * * \\
(4.33)\end{array}$ & & & & & & \\
\hline ipoll & & & & & $\begin{array}{l}1.399 \\
(1.12)\end{array}$ & $\begin{array}{l}0.728 \\
(0.66)\end{array}$ & & & & \\
\hline wast & & & & & & & $\begin{array}{c}-0.341^{* * *} \\
(-3.96)\end{array}$ & $\begin{array}{c}-0.385^{* * *} \\
(-3.48)\end{array}$ & & \\
\hline sulf & & & & & & & & & $\begin{array}{c}-0.234^{* * *} \\
(-3.12)\end{array}$ & $\begin{array}{c}-0.212 * * \\
(-2.46)\end{array}$ \\
\hline $\begin{array}{c}\text { Control } \\
\text { variables }\end{array}$ & controlled & controlled & controlled & controlled & controlled & controlled & controlled & controlled & controlled & controlled \\
\hline $\begin{array}{l}\text { Sample } \\
\text { capacity }\end{array}$ & 386 & 389 & 386 & 389 & 386 & 389 & 386 & 389 & 386 & 389 \\
\hline
\end{tabular}

Note: ${ }^{* *}$ and ${ }^{* * *}$ respectively indicate that the estimated coefficients are significant at the levels of 0.05 and 0.01 , and the constant term estimation is omitted.

\subsection{Heterogeneity Analysis}

The results of the previous test show that environmental governance has an important impact on the fishery economic development. On the whole, the increase of environmental governance intensity will improve the level of fishery economic development. In addition, the impact of environmental governance on fishery economic growth will be different in different regions and different periods. In order to explore the differential impact of environmental governance, we further analyze the environmental governance effects in different regions and different periods.

\subsubsection{Spatial Heterogeneity}

According to the classification standard of the government and the general classification of literature, 31 provinces in China are divided into eastern, central and western regions, and the spatial heterogeneity analysis is carried out on this basis. The test results are shown in Table 5. Overall, the impact of environmental governance on fishery economic growth is the most significant in the eastern region, followed by the central region, and environmental governance has a positive impact on fishery economy in the eastern and central regions; in contrast, the impact of environmental governance on fishery economic growth in the western region is less significant and shows negative.

Table 5. Environmental governance and fishery economic growth: spatial heterogeneity. (The iterative GMM method.).

\begin{tabular}{|c|c|c|c|c|c|c|c|c|c|c|c|c|}
\hline Variables & $\begin{array}{c}\text { Model } \\
1\end{array}$ & $\begin{array}{c}\text { Model } \\
2\end{array}$ & $\begin{array}{c}\text { Model } \\
3\end{array}$ & $\underset{4}{\text { Model }}$ & $\begin{array}{c}\text { Model } \\
5\end{array}$ & $\underset{6}{\text { Model }}$ & $\begin{array}{c}\text { Model } \\
7\end{array}$ & $\begin{array}{c}\text { Model } \\
8\end{array}$ & $\begin{array}{c}\text { Model } \\
9\end{array}$ & $\begin{array}{c}\text { Model } \\
10\end{array}$ & $\begin{array}{c}\text { Model } \\
11\end{array}$ & $\begin{array}{c}\text { Model } \\
12\end{array}$ \\
\hline & \multicolumn{4}{|c|}{ in the eastern region } & \multicolumn{4}{|c|}{ in the central region } & \multicolumn{4}{|c|}{ in the western region } \\
\hline & afis & tfis & afis & tfis & afis & tfis & afis & tfis & afis & tfis & afis & tfis \\
\hline indu & $\underset{* * *}{0.284}$ & $\underset{* * *}{0.502}$ & & & -0.588 & $1.104^{* *}$ & & & $-\underset{*}{0.214}$ & $-\underset{*}{0.090}$ & & \\
\hline & $(2.96)$ & $(3.29)$ & & & $(-0.56)$ & $(2.55)$ & & & $(-1.85)$ & $(-1.81)$ & & \\
\hline \multirow[t]{2}{*}{ poll } & & & 3.996 & $\underset{* * *}{5.458}$ & & & 1.718 & $\underset{* * *}{4.728}$ & & & 2.309 & -0.417 \\
\hline & & & $(3.91)$ & (3.61) & & & $(0.96)$ & $(4.26)$ & & & (1.07) & $(-0.69)$ \\
\hline $\begin{array}{c}\text { Control } \\
\text { vari- } \\
\text { ables }\end{array}$ & controlled & controlled & controlled & controlled & controlled & controlled & controlled & controlled & controlled & controlled & controlled & controlled \\
\hline $\begin{array}{l}\text { Sample } \\
\text { capac- } \\
\text { ity }\end{array}$ & 142 & 142 & 142 & 142 & 104 & 104 & 104 & 104 & 140 & 143 & 140 & 143 \\
\hline
\end{tabular}

Note: ${ }^{*}, * *$ and ${ }^{* * *}$ respectively indicate that the estimated coefficients are significant at the levels of $0.1,0.05$ and 0.01, and the constant term estimation is omitted. 


\subsubsection{Temporal Heterogeneity}

According to the distribution of selected data samples, this paper divides the time of sample from 2004 to 2017 into stages and analyzes the impact level of environmental governance on the fishery economic development in different time periods. The test results are shown in Table 6. Overall, in the period 2009-2013, environmental governance has a great promotional effect on the fishery economic growth. Individually, for the industrial pollution control variable, both the promotional effect and the influential significance of environmental governance on fishery economic growth show the trend of rising first and then decreasing; for the environmental pollution control variable, there was no significant impact in the periods 2004-2008 and 2014-2017, and only in the period 2009-2013 is the impact significant.

Table 6. Environmental governance and fishery economic growth: temporal heterogeneity. (The iterative GMM method).

\begin{tabular}{|c|c|c|c|c|c|c|c|c|c|c|c|c|}
\hline Variables & $\begin{array}{c}\text { Model } \\
1\end{array}$ & $\begin{array}{c}\text { Model } \\
2\end{array}$ & $\begin{array}{c}\text { Model } \\
3\end{array}$ & $\underset{4}{\text { Model }}$ & $\begin{array}{c}\text { Model } \\
5\end{array}$ & $\underset{6}{\text { Model }}$ & $\begin{array}{c}\text { Model } \\
7\end{array}$ & $\begin{array}{c}\text { Model } \\
8\end{array}$ & $\begin{array}{c}\text { Model } \\
9\end{array}$ & $\begin{array}{c}\text { Model } \\
10\end{array}$ & $\begin{array}{c}\text { Model } \\
11\end{array}$ & $\begin{array}{c}\text { Model } \\
12\end{array}$ \\
\hline & \multicolumn{4}{|c|}{ 2004-2008 } & \multicolumn{4}{|c|}{ 2009-2013 } & \multicolumn{4}{|c|}{$2014-2017$} \\
\hline & afis & tfis & afis & tfis & afis & tfis & afis & tfis & afis & tfis & afis & tfis \\
\hline \multirow[t]{2}{*}{ indu } & $0.232 * *$ & $0.324 * *$ & & & 0.287 & 0.725 & & & $0.231^{* *}$ & $0.415^{* *}$ & & \\
\hline & $(2.54)$ & $(2.36)$ & & & $(2.94)$ & (5.72) & & & (2.19) & $(2.40)$ & & \\
\hline \multirow[t]{2}{*}{ poll } & & & -2.063 & -2.479 & & & $\underset{* * *}{6.946}$ & $4.942 * *$ & & & 0.112 & 0.437 \\
\hline & & & $(-1.61)$ & $(-1.26)$ & & & $(2.86)$ & $(2.16)$ & & & $(0.06)$ & $(0.13)$ \\
\hline $\begin{array}{c}\text { Control } \\
\text { vari- } \\
\text { ables }\end{array}$ & controlled & controlled & controlled & controlled & controlled & controlled & controlled & controlled & controlled & controlled & controlled & controlled \\
\hline $\begin{array}{l}\text { Sample } \\
\text { capacity }\end{array}$ & 118 & 120 & 118 & 120 & 149 & 150 & 149 & 150 & 119 & 119 & 119 & 119 \\
\hline
\end{tabular}

Note: ${ }^{* *}$ and ${ }^{* * *}$ respectively indicate that the estimated coefficients are significant at the levels of 0.05 and 0.01 , and the constant term estimation is omitted.

\subsection{Robustness Analysis}

Finally, considering the stability and reliability of the model test results, the robustness test is needed to verify the accuracy of the above model estimation results. This paper mainly tests the robustness of the model through the following two methods. First, replace variables. We mainly replace the proxy variables of environmental governance with the proportion of environmental pollution control investment in GDP, the intensity of wastewater discharge and the intensity of sulfur dioxide emission, and then empirically test Formula (1) respectively again. Among them, the proportion of environmental pollution control investment in GDP is a positive agency index of environmental governance. The larger the ratio is, the greater the intensity of environmental governance is. The wastewater discharge intensity and the sulfur dioxide emission intensity are the reverse agency indexes of environmental governance. The higher the intensity is, the lower the level of environmental governance is. The test results are shown in Table 7 . The estimation results show that both the significance of the variables and the sign of the estimated coefficient are significantly changed, which can explain the stability of the above model test results to a certain extent. Second, consider the endogenous test of the model. The test results are shown in Table 4 . The specific analysis is the same as the above description of endogenous test, which will not be repeated here. 
Table 7. Robustness test.

\begin{tabular}{|c|c|c|c|c|c|c|}
\hline Variables & Model 1 & Model 2 & Model 3 & Model 4 & Model 5 & Model 6 \\
\hline & afis & tfis & afis & tfis & afis & tfis \\
\hline ipoll & $\begin{array}{c}1.448^{* * *} \\
(3.43)\end{array}$ & $\begin{array}{l}0.514 \\
(1.27)\end{array}$ & & & & \\
\hline wast & & & $\begin{array}{c}-0.510 * * * \\
(-5.94)\end{array}$ & $\begin{array}{c}-0.638^{* * *} \\
(-8.27)\end{array}$ & & \\
\hline sulf & & & & & $\begin{array}{c}-0.201 \text { ** } \\
(-2.38)\end{array}$ & $\begin{array}{c}-0.193 \text { ** } \\
(-2.41)\end{array}$ \\
\hline Control variables & controlled & controlled & controlled & controlled & controlled & controlled \\
\hline Sample capacity & 415 & 419 & 415 & 419 & 415 & 419 \\
\hline
\end{tabular}

Note: ${ }^{* *}$ and ${ }^{* * *}$ respectively indicate that the estimated coefficients are significant at the levels of 0.05 and 0.01 , and the constant term estimation is omitted.

\section{Conclusions and Suggestions}

\subsection{Conclusions}

Fishery is a resource- and environment-dependent industry; without the harmonious coexistence of fishery resources and ecological environment, there will be no healthy, stable and sustainable development and modernization of fishery. With China's economy entering the new normal, environmental problems have seriously become a weak point restricting the development of China's fishery economy, facing a big bottleneck. Therefore, how to coordinate the relationship between environmental governance and fishery development, so as to explore a road suitable for high-quality development of fishery, is the main direction to promote the supply-side structural reform of fishery and the construction of modern fishery, which is of great significance to ensure national food security, resource security and ecological security, as well as accelerate the construction of a beautiful country and maritime power.

In this context, this paper uses panel data to empirically analyze the impact relationship and action path between environmental governance and fishery economic development, and further explores the heterogeneity in spatial and temporal aspects of this impact. The results show that, first of all, on the whole, environmental governance significantly promotes fishery economic development. Whether the level of fishery economic development is measured only by the amount of investment in industrial pollution control or by the amount of investment in environmental pollution control, the effect of environmental governance on fishery economic growth is obvious. Secondly, the effects of environmental governance on the development of fishery economy are different in spatial and temporal aspects. That is to say, the impact of environmental governance on fishery economic growth will be different in different regions and different periods. In terms of regional characteristics, the impact of environmental governance on fishery economic development shows the distribution characteristic of "in the eastern region $>$ in the central region $>$ in the western region". The specific performance is as follows: the impact of environmental governance on fishery economic growth is the most significant in the eastern region, followed by the central region, and environmental governance has a positive impact on fishery economy in the eastern and central regions; in contrast, the impact of environmental governance on fishery economic growth in the western region is less significant and shows negative. From the perspective of timing change, this shows an "inverted $U$ " type timing change characteristic of "influence degree rising - influence degree decreasing". The specific performance is as follows: In the period 2009-2013, environmental governance has a great promotional effect on the fishery economic growth. Individually, for the industrial pollution control variable, both the promotional effect and the influential significance of environmental governance on fishery economic growth show the trend of rising first and then decreasing; for the environmental pollution control variable, there was no significant impact in the periods 2004-2008 and 2014-2017, and only in the period 2009-2013 is the impact significant. Finally, the identification of transmission mechanism further reveals 
that technological innovation can play a certain mediating role between environmental governance and fishery economic growth. With improving the level of technological innovation, environmental governance has a significant impact on fishery economic growth. In the process of exploring agricultural modernization, technological innovation may become an effective way to balance environment and fishery economic development.

The contribution of this paper is embodied in the following: First, it enriches the literature on environmental governance and fishery economy development, conducts an in-depth analysis of the relationship between the two from the perspective of empirical research, and discovers the dynamic balance relationship between environmental governance and fishery economy development. Secondly, when constructing the indicator system of environmental governance and fishery economy development, it covers multiple angles, avoiding the one-sidedness of selecting a single indicator for factor analysis, and the analysis results obtained are more referential. In the end, both the starting point and the end point of the research paid great attention to its practical guiding significance, and very practical policy recommendations were put forward.

In addition, although some results have been achieved, there are still many shortcomings in the research process, mainly in the field of multidisciplinary knowledge involved in this article. The related knowledge involves environmental economics, development economics, management, statistics, etc. In the writing of the thesis, this article introduces appropriate quantitative analysis methods. However, due to the fact that China's fishery statistical data is relatively small at present, the available statistical data is limited in years, and there are inconsistencies in the statistical caliber. Some analysis cannot be further carried out, which affects the depth of the research. From the perspective of research, bound by the research data, this article mainly starts from the perspective of the industry, and does not take into account the important role of the enterprise as an economic entity in the fishery economy, which affects the comprehensiveness of the final policy recommendations to a certain extent.

\subsection{Suggestions}

Due to overfishing, environmental pollution and other reasons, traditional fishery resources are declining, the marine ecological environment is deteriorating and many other problems are seriously affecting the sustainable utilization of fishery resources. Based on the above research conclusions, to coordinate the dynamic equilibrium between environmental governance and fishery economic development and promote sustainable development, the following policy suggestions are put forward:

First, promote environmental governance and protection through technological innovation. There is no contradiction between environmental governance and fishery economic development. Environmental governance is conducive to creating a more healthy and fair development environment, promoting the transformation and upgrading of fishery industrial structure, and advancing the high-quality development of fishery economy. Technological innovation is the key point to giving consideration to both environmental protection and fishery economic development. Technological innovation can not only green the high-energy consumption and high-pollution technology, but also green the fishery technology, so as to promote the mutual promotion relationship between environmental governance and fishery economic development. We should do these things-explore the establishment of a comprehensive governance system that integrates coastal areas, drainage areas and sea areas; strictly control the sea reclamation, strengthen the comprehensive management of coastal zone and coastal wetland protection; expand the scope of total emission control of pollutants into the sea, and ensure the water quality of river sections into the sea; accelerate the comprehensive governance of key sea areas and enhance our ability to cope with marine natural disasters and environmental emergencies; promote energy conservation, consumption reduction, green environmental protection, increase production and increase income in fishery industry, and apply Internet of Things technology to build a modern fishery cloud service platform; improve the level of aquaculture 
production management and information management, and promote the transformation and upgrading of fishery; and actively carry out environmental improvement to promote the safety, civilization and sustainable development of fishery industry.

Second, develop regional environmental governance and structural fishery industry. On the whole, in the eastern region fishery is prosperous, but due to social pressure and other factors, its development has entered a bottleneck period. In dealing with the relationship between environment and fishery development, the eastern region should highlight the positive role of environmental governance and take ecological restoration as an important point to promote the high-quality development of the fishery economy. In terms of scale or time, there is a significant gap between the development of fishery in the central and western regions and that in the eastern region. Under the constraints of resources, environment and other factors, the central and western regions should pay more attention to the diversified development of fishery industry and make overall plans for leisure fishery and ocean fishery.

Third, lead the transformation and upgrading of fishery with green development. In terms of development mode, we should transform from an extensive and high-consumption type to an economical and efficient type, optimize production structure and rationalize a regional layout. It is also important to highlight green solutions, effectively solve the contradiction between fishery development and ecological environment protection, and then explore a "green and low-carbon, friendly environment, resource protection, quality and safety" development direction.

Author Contributions: Data curation, J.Y. and H.C.; Formal analysis, H.C.; Funding acquisition, D.Z. and W.L.; Investigation, J.Y.; Methodology, N.H.; Supervision, W.L. and N.H.; Writing—original draft preparation, N.H. and Q.Z.; Writing-review and editing, D.Z. and Q.Z. All authors have read and agreed to the published version of the manuscript.

Funding: This research was funded by Research topics on major forestry issues in 2014, Chinese National Forestry and Grassland Ad-ministration [grant number ZDWT201415] and The Mining Growth Opportunities from Customer Experience: A Deep Case Study [grant number 2020HXZXJGXY003].

Institutional Review Board Statement: Not applicable.

Informed Consent Statement: Not applicable.

Data Availability Statement: Restrictions apply to the availability of these data. Data was obtained from China Statistical Yearbook, China Rural Statistical Yearbook, China Agriculture Yearbook, etc. and are available at http:/ / www.stats.gov.cn/, accessed on 30 August 2021.

Conflicts of Interest: The authors declare no conflict of interest.

\section{References}

1. The General Office of the Central Committee of the Communist Party of China and the General Office of the State Council issued the Guiding Opinions on the Construction of Modern Environmental Governance System. Bull. State Counc. People's Repub. China 2020, 8, 11-14.

2. Zhang, R. Collaborative integration and system design of environmental governance. Academia 2020, 9, 93-101.

3. Wang, S. Environmental governance is an important part of national governance. Leg. Syst. Soc. Dev. 2014, $20,51-53$.

4. Du, J.; Yi, H. Target-setting, political incentives, and the tricky trade-off between economic development and environmental protection. Public Adm. 2021. [CrossRef]

5. Dinda, S. Environmental Kuznets curve hypothesis: A survey. Ecol. Econ. 2004, 49, 431-455. [CrossRef]

6. Xin, L.; Chen, J.; An, X. Evaluation of my country's Fishery Modernization Development Level. China Agric. Resour. Reg. Plan. 2020, 41, 140-149.

7. Cui, Z.; Qu, K.; Tang, Q. Fishery environment facing situation and sustainable development strategy research. China Eng. Sci. 2018, 20, 63-68. [CrossRef]

8. Gao, J.; Li, J.; Liu, T. Analysis of the consumer demand trends and influencing factors of Chinese aquatic products. Dongyue Lun Cong 2013, 34, 118-123.

9. D'Arge, R.C. Essay on Economic Growth and Environmental Quality. Swed. J. Econ. 1971, 73, 25-41. [CrossRef]

10. Forster, B.A. A Note on Economic Growth and Environmental Quality. Swed. J. Econ. 1972, 74, 81-85. [CrossRef]

11. Forster, B.A. Optimal Capital Accumulation in a Polluted Environment. South. Econ. J. 1973, 39, 44-47. [CrossRef] 
12. Xu, C.; Mu, H. Considerations on environmental issues in sustainable development. J. Shanxi Univ. Financ. Econ. 2000, 5, 51-53.

13. Zhang, B.; Zuo, H. Sustainable use of energy, environmental governance and endogenous economic growth. China Popul. Resour. Environ. 2007, 5, 27-32.

14. Dai, G.; An, P.; Gao, J. An Empirical Study on the Relationship between Environmental Governance Investment and Economic Growth from the Perspective of Environmental Carrying Capacity—Based on Inter-provincial Panel Data. J. Ocean. Univ. China (Nat. Sci. Ed.) 2010, 40, 137-144.

15. Huang, J.; Chen, S. Environmental Pollution Control and Economic Growth: Models and China's Empirical Research. Nankai Econ. Res. 2011, 1, 142-152.

16. Chen, S.; Xu, S.; Ouyang, Z.; Liang, Z.; Fan, B. An Empirical Study on the Relationship between China's Industrial Pollution Control Investment and Economic Growth-An Analysis Based on Panel Data of 10 Provinces and Cities. Sci. Decis. 2015, 2, 43-54.

17. Zhang, Y. Environmental governance investment and economic growth: Theoretical and empirical research. East China Econ. Manag. 2016, 30, 150-156.

18. Chang, H.; Wang, J. Research on the Impact of Environmental Regulation on Economic Growth—Based on the Empirical Analysis of Technological Innovation Threshold. Explor. Econ. Issues 2020, 11, 41-51.

19. Yao, J. Environmental Economics; Southwestern University of Finance and Economics Press: Chengdu, China, 2001.

20. Grossman, G.M.; Krueger, A.B. Economic Growth and the Environment. Q. J. Econ. 1995, 110, 353-377. [CrossRef]

21. Panayotou, T. Demystifying the environmental Kuznets curve: Turning a black box into a policy tool. Environ. Dev. Econ. 1997, 2, 465-484. [CrossRef]

22. Sadik-Zada, E.R.; Gatto, A. The puzzle of greenhouse gas footprints of oil abundance. Socio-Econ. Plan. Sci. 2021, 75, 100936. [CrossRef]

23. Sadik-Zada, E.R.; Ferrari, M. Environmental Policy Stringency, Technical Progress and Pollution Haven Hypothesis. Sustainability 2020, 12, 3880. [CrossRef]

24. Ding, L.; Zheng, H.; Liu, X. Evaluation of marine economic production efficiency, environmental governance efficiency and overall efficiency. Forum Sci. Technol. China 2018, 3, 48-57.

25. Huang, Y.; Du, Q.; Wang, X. The impact of water pollution on the development of coastal fisheries in our province and its countermeasures. Fujian Fish. 1992, 2, 70-72.

26. Jia, J. Protecting the environment is the top priority for the sustainable development of fisheries. Freshw. Fish. 1997, 4, 26-29.

27. Han, W. The impact of the marine environment on fisheries and the control measures. China Fish. 2004, 5, 30-31.

28. Bi, J.; Duan, Z. My country's marine fishery ecological environment pollution and control countermeasures. Chin. Fish. Econ. 2008, 2, 16-21.

29. Fu, G.; Ru, Y.; Kong, F. Research on Cooperative Governance of Marine Fishery Environmental Pollution: Taking the Yangtze River Delta as an Example. Adm. Forum 2014, 21, 72-76.

30. Lynch, A.J.; Elliott, V.; Phang, S.C.; Claussen, J.E.; Harrison, I.; Murchie, K.J.; Steel, E.A.; Stokes, G.L. Inland fish and fisheries integral to achieving the Sustainable Development Goals. Nat. Sustain. 2020, 3, 579-587. [CrossRef]

31. Lynch, A.J.; Bartley, D.M.; Beard, T.D., Jr.; Bunnell, D.B.; Cooke, S.J.; Cowx, I.G.; Funge-Smith, S.; Paukert, C.P.; Rogers, M.W. InFish: A Professional Network to Promote Global Conservation and Responsible Use of Inland Fish. Fisheries 2020, 45, 319-326. [CrossRef]

32. Wen, Z.; Zhang, L.; Hou, J.; Liu, H. Intermediary effect test procedure and its application. Psychol. Bull. 2004, 5, 614-620. 